\title{
Discrimination learning using different CS-US intervals in classical conditioning of the rabbit's nictitating membrane response
}

\author{
E. JAMES KEHOE, PETER S. HORNE, and AMANDA J. HORNE \\ University of New South Wales, Sydney, Australia
}

\begin{abstract}
Differential conditioning of the rabbit's nictitating membrane (NM) response was examined when two CSs each signaled the US, but at different CS-US intervals (e.g., 200 and $600 \mathrm{msec}$ ). For each subject, one CS was a $600-\mathrm{Hz}$ tone, and the other CS was either a $2100-, 1000-$, or $660-\mathrm{Hz}$ tone. This task took advantage of the distinctive temporal character of the NM conditioned response (CR); namely, the NM closure reaches its peak near the point of US delivery. The distribution of CR peaks around the points of US delivery varied as a function of the difference between the tones. For the differences that were "easy" (600 vs. $2100 \mathrm{~Hz}$ ) and "medium" (600 vs. $1000 \mathrm{~Hz}$ ), the distributions overlapped but conformed to their CS-US intervals. For the "hard" difference $(600 \mathrm{vs} .660 \mathrm{~Hz})$, the distributions overlapped entirely. In an analysis of individual subjects using signal detection measures, half the subjects showed very high degrees of sensitivity to the easy and medium tone differences. The remaining subjects in those two groups showed high response biases that obscured any sensitivity. For the hard tonal difference, there was no evidence of sensitivity, and variation between subjects reflected only variation in response bias. The results suggest that this task can help illuminate the neural basis of encoding for the sensory and temporal differences among CSs in a useful way.
\end{abstract}

In this study, differential conditioning of the rabbit's nictitating membrane (NM) response to tones of different frequencies was examined. Traditionally, differential conditioning has entailed a go/no-go procedure in which one conditioned stimulus (CS+) is paired with the unconditioned stimulus (US) and a second conditioned stimulus (CS-) is presented alone (e.g., Pavlov, 1927). In the present experiments, the two CSs (CSA, CSB) each signaled the US, but at different CS-US intervals (e.g., 200 and $600 \mathrm{msec}$ ). This task took advantage of the distinctive temporal character of conditioned responses (CRs) in the NM preparation; they are highly attuned to the CS-US interval. Most notably, the NM's extension reaches maximal closure-the CR peak-around the time at which the US was delivered on previous trials (e.g., Coleman \& Gormezano, 1971; Millenson, Kehoe, \& Gormezano, 1977; Smith, 1968). Furthermore, electrophysiological studies have revealed a close correspondence between the CR's time course and the time course of neural firings at several sites in the brain, which include the abducens nucleus (Cegavske, Patterson, \& Thompson, 1979; Young, Cegavske, \& Thompson, 1976), accessory abducens nucleus (Disterhoft, Quinn, Weiss, \& Shipley, 1985), the hippocampus (Berger \& Thompson, 1978;

Preparation of this manuscript was supported by Australian Research Council Grant AC9231222. Correspondence should be sent to E. J. Kehoe, School of Psychology, University of New South Wales, P.O. Box 1, Kensington, NSW 2033, Australia.
Weisz, Clark, \& Thompson, 1984), the cerebellum (Berthier \& Moore, 1986, 1990; McCormick \& Thompson, 1984), and red nucleus (Desmond \& Moore, 1991).

In classical conditioning, the study of discrimination learning and its psychophysics has been limited to the go/no-go task. In that task, the occurrence of a CR can be treated safely as a "yes" response affirming that the stimulus was detected and recognized, either rightly or wrongly, as CS + (Suboski, 1967). The absence of a CR, however, cannot be treated safely as a "no" response. The absence of a CR tells us little about the stage of processing at which the failure in responding occurred. For example, the absence of a CR could mean (1) the subject failed to detect the stimulus, (2) the subject detected the stimulus but failed to recognize it as a CS, or (3) the subject perceived the stimulus as the CS - and withheld the CR. This ambiguity at the behavioral level is equally acute when one attempts to establish whether there is a correspondence between the $C R$ and neural activity. Depending on why the CR failed to occur, different patterns of neural activity could occur, but there would be no behavioral differences with which to correlate them.

Unlike the conventional go/no-go procedure, different CS-US intervals each produce a definite "correct" response for each CS and, thereby, a definite "incorrect" response. Failures to make either response could then be distinguished at behavioral and neural levels from the different CRs. Empirically, there have been two demonstrations that rabbits acquire temporally distinct CRs when the two CSs are highly distinctive. First, Kehoe, Graham- 
Clarke, and Schreurs (1989) intermixed trials in which a light CS signaled the US at an interval of $600 \mathrm{msec}$ and a tone CS signaled the US at an interval of $1,600 \mathrm{msec}$. The rabbits acquired a CR to the light that peaked around $600 \mathrm{msec}$ after stimulus onset and a CR to the tone that peaked around $1,600 \mathrm{msec}$. Second, Mauk and Ruiz (1992) used two tones of 400 and $8000 \mathrm{~Hz}$ paired with the US at a variety of intervals. The shorter interval was either 150 or $250 \mathrm{msec}$; the longer interval was 250,500 , 750 , or $1,000 \mathrm{msec}$. In each case, the rabbits acquired CRs appropriate to the CS-US intervals.

Although differential conditioning based on CS-US intervals appears promising, questions about its suitability for the refined study of psychophysics in classical conditioning remain. First, it is unknown whether distinctive CRs will appear if the physical difference between the CSs is reduced so that their sensory representations overlap. Kehoe et al. (1989) addressed this question by examining whether rabbits could differentiate between a tone + light compound and its components on the basis of different CS-US intervals. In go/no-go procedures, such differentiations can be established, sometimes with relatively brief training (Kehoe, 1986; Kehoe \& Graham, 1988). However, in Kehoe et al. (1989), differential responding was poor when the compound signaled the US at one CS-US interval (e.g., $600 \mathrm{msec}$ ) and separate presentations of the tone and the light signaled the US at another CS-US interval (e.g., 1,600 msec). Usually, two peaks appeared, one at $600 \mathrm{msec}$ and the other at $1,600 \mathrm{msec}$ after stimulus onset on all trials. Thus, differentiation based on CS-US intervals may not be robust enough for psychophysical research.

If distinctive CRs can be established on a group basis, the consistency of the differentiation both within and between individual subjects needs to be determined. For studies using neural recording, stimulation, and/or lesion techniques, data from individual subjects are crucial in detecting a relationship between neural activity and behavior. Mauk and Ruiz (1992) found that differentiation was large and relatively consistent across individual subjects when the CSs were highly distinctive. However, for CSs that are more similar, differences may be smaller and individual variation may become greater. Consistency within individuals coupled with some variation between individuals at the behavioral and neural levels would be useful in detecting correlations between the two levels.

In addition to issues of psychophysics, differential conditioning based on different CS-US intervals has implications for understanding the time course of the CR in both behavioral and neural terms. The most prominent accounts of the CR's time course are the "real-time" models. The purely behavioral models presume that the CS activates a cascade of hypothetical stimuli (Desmond, 1990; Gluck, Reifsnider, \& Thompson, 1990; Grossberg \& Schmajuk, 1989; Sutton \& Barto, 1990). In a similar fashion, other models of this class assume that the CS activates different neurons at different times (Buonomano \& Mauk, 1991; Moore, Desmond, \& Berthier, 1989).
Whether the elements are hypothetical or neural, the realtime models assume that there is a temporal encoding of the CS into a set of time-dependent zones. The elements in zones that overlap the US are presumed to gain the greatest associative strength. Hence, on later presentations of the CS, the CR peak tends to appear near US delivery where the elements with the greatest associative strength coincide.

For purposes of both sensory differentiation and temporal encoding in the rabbit NM preparation, the neural representation of the CS appears to project to the cerebellum through the mossy fibers (Steinmetz, Logan, \& Thompson, 1988; Steinmetz et al., 1987; Steinmetz, Rosen, Chapman, Lavond, \& Thompson, 1986). These fibers each branch profusely and contact up to 1,000 cerebellar granule cells (e.g., Ito, 1984). This structure seems well suited for simultaneously encoding both sensory and temporal dimensions of a CS by using different subsets of mossy fibers for different CSs and/or different times following CS onset (cf. Moore \& Blazis, 1989; Moore et al., 1989). In particular, Mauk and Ruiz (1992) have offered a sequential encoding hypothesis. They suggest that the temporal encoding of the CS resides in the activation of different subsets of granule cells. The mossy fibers are thought to encode "CS input," which would include the sensory features of the CS.

\section{EXPERIMENT 1}

The general aim was to determine whether differential conditioning based on two CS-US intervals is suitable for the study of sensory encoding of CSs and its integration with temporal encoding. In Experiment 1, we examined differential conditioning by using three pairs of tonal frequencies. The tone pairs were (1) 600 versus $2100 \mathrm{~Hz}$, (2) 600 versus $1000 \mathrm{~Hz}$, and (3) 600 versus $660 \mathrm{~Hz}$. In previous findings using go/no-go procedures, the first pair was an easy discrimination that yielded clear differential responding. The second pair also yielded good differentiation, but the third pair yielded no discernible differentiation (Poulos, Kehoe, \& Gormezano, 1985). In the present experiment, the CS-US interval was manipulated between CSs. For one CS in each pair, the US was presented $200 \mathrm{msec}$ after CS onset; for the other CS, the US was presented $600 \mathrm{msec}$ after CS onset. In order to identify the location of the CR peak without an intrusion from the UR (unconditioned response), the rabbits were presented periodically with test trials for each CS without the US.

\section{Method}

Subjects. The subjects were 24 naive, female albino rabbits (Oryctolagus cuniculus), each 70-80 days old and weighing approximately $1.5 \mathrm{~kg}$ on arrival from the university's breeding unit. The animals had free access to food and water in their home cages.

Apparatus. The apparatus and recording procedure for the NM response were patterned after those of Gormezano (1966) and are detailed by Kehoe, Feyer, and Moses (1981). The CSs were pure tones of $650 \mathrm{msec}$ in duration and $94 \mathrm{~dB}$ (SPL) in intensity, superimposed on an ambient noise level of $81 \mathrm{~dB}$. The US was a 50 - 
msec, 3-mA, 50-Hz electric current delivered via 9-mm stainless steel Autoclip wound clips positioned $10 \mathrm{~mm}$ apart and $15 \mathrm{~mm}$ posterior to the lateral canthus of the right eye. The sequence and timing of stimulus events were controlled by an Apple II computer equipped with interfaces and software developed by Scandrett and Gormezano (1980).

To monitor movements of the NM, a small wire hook was attached to a silk loop sutured in the NM of the animal's right eye. The other end of the hook contained a loop that fitted over the curved end of an L-shaped piano wire crank, which operated a photoelectric transducer (Gormezano \& Gibbs, 1988). The signal from the transducer was amplified and transmitted to an analog/digital converter installed in the computer. No straps were used to retract the external eyelids.

Procedure. All the animals received 1 day of preparation, 2 days of rest, 1 day of adaptation, and $\mathbf{8}$ days of training. On the preparation day, hair posterior to the animal's right eye was shaved, a small loop of silk (000 Dynex) was sutured into the right NM, and the animals were returned to their home cages for 2 days. On the adaptation day, the animals were placed into the conditioning apparatus for $60 \mathrm{~min}$, but neither a CS nor US was presented.

Following adaptation, the animals were assigned to one of three groups $(n=8)$. They were denoted as Groups E, M, and H, standing for "easy," "medium," and "hard," respectively. Specifically, Group E received training with the $600-\mathrm{Hz}$ and $2100-\mathrm{Hz}$ tones. Group $\mathrm{M}$ received the $600-\mathrm{Hz}$ and $1000-\mathrm{Hz}$ tones, and Group $\mathrm{H}$ received the $600-\mathrm{Hz}$ and $660-\mathrm{Hz}$ tones. For Days $1-5$, each training session contained 30 trials in which one tone (CSA) was paired with the US at a CS-US interval of $200 \mathrm{msec}$, and 30 trials in which the other tone (CSB) was paired with the US at an interval of $600 \mathrm{msec}$. The CSA-US and CSB-US trials were intermixed such that there were no more than two of one type in a row. For half the animals in each group, CSA was the $600-\mathrm{Hz}$ tone, and CSB was the other tone. For the other half of the animals, CSB was the $600-\mathrm{Hz}$ tone, and CSA was the other tone. On Days 6-8, every fifth trial was a test trial for either CSA alone or CSB alone, for the first 60 trials. All together, six CSA-alone and six CSBalone test trials were substituted for the same number of CSA-US and CSB-US trials, respectively. The mean intertrial interval was $60 \mathrm{sec}$ (range $=50-70 \mathrm{sec}$ )

CR definition and statistical analyses. A CR on a CS-US trial was defined as an extension of the NM exceeding $0.5 \mathrm{~mm}$ occurring between CS onset and US onset (Marshall-Goodell, Schreurs, \& Gormezano, 1982). On test trials, the observation interval was extended to $1,400 \mathrm{msec}$ following CS onset. If a CR occurred, a twin-peak response was defined by using criteria established in previous research (Kehoe, P. S. Horne, Macrae, \& A. J. Horne, 1993; Millenson et al., 1977). Specifically, a twin peak was defined by an initial NM extension greater than $1 \mathrm{~mm}$, followed by a retraction of at least $1 \mathrm{~mm}$ and a second extension of $1 \mathrm{~mm}$ or more. The CR measurements were analyzed by using planned contrasts, and the Type I error rate $(\alpha)$ was set at .05 .

\section{Results}

Group CR peak distributions. Figure 1 shows the mean proportion of $\mathrm{CR}$ peaks appearing in each of six 200-msec bins following CS onset (1-199, 200-399, etc.) on test trials. There is a separate panel for each group. Within each panel, there is a separate distribution for CSA and CSB.

Inspection of Figure 1 reveals that the CR peaks tended to appear shortly after the points at which the US occurred on training trials. That is to say, peaks were clustered in the 200-399 bin and/or the 600-799 bin. If differentiation had been perfect, all the CR peaks on CSA trials would have appeared in the 200-399 bin, and all the CR

\section{EXPERIMENT 1 - PEAK LATENCIES}
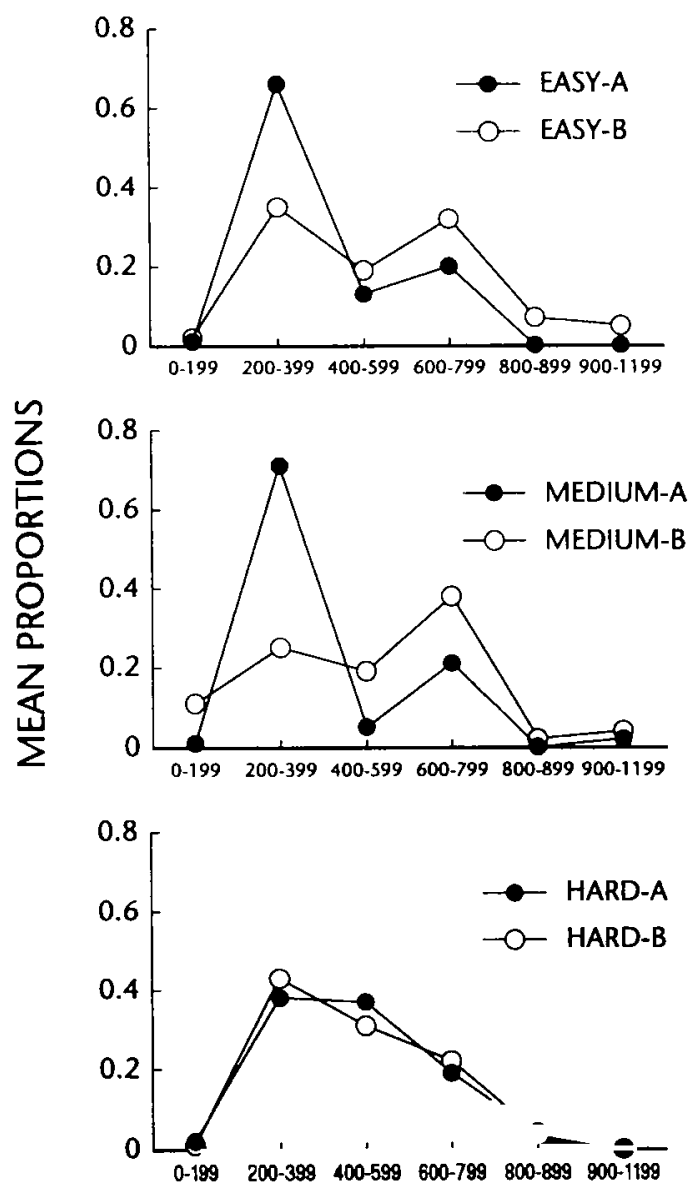

TIME SINCE CS ONSET - 200-ms BINS

Figure 1. The mean proportion of $\mathrm{CR}$ peaks appearing in each of six 200-msec bins following stimulus onset on CSA and CSB test trials in Experiment 1. (Each bin is labeled by its lower and upper boundary. There is a separate panel for each group.)

peaks on CSB trials would have appeared in the 600-799 bin. The group distributions suggest that differentiation was less than perfect, even for Group E. Nevertheless, there were systematic differences among the distributions as a function of the CS-US intervals and the group manipulation of tonal frequency.

In Group E, significant differences appeared between CSA and CSB that were consistent with their respective CS-US intervals. Specifically, CSA, which signaled the 200-msec CS-US interval, had two thirds of its peaks in the 200-399 bin $(M=66 \%)$. In contrast, CSB, which signaled the 600 -msec CS-US interval, had only one third of its peaks in the 200-399 bin $[M=35 \%, F(1,21)=$ $19.40, p<.01]$. In the $600-799$ bin, the difference was smaller but in the appropriate reverse direction. That is to say, CSA and CSB had, respectively, $20 \%$ and $32 \%$ of their peaks in that bin $[F(1,21)=5.66, p<.05]$. 
The pattern of responding for Group $M$ was similar to that of Group E. In the 200-399 bin, CSA $(M=71 \%)$ produced more peaks than CSB $[M=25 \%, F(1,21)=$ $44.07, p<.01]$. Conversely, in the $600-799$ bin, CSA produced fewer peaks $(M=21 \%)$ than did CSB [ $M=$ $38 \%, F(1,21)=12.35, p<.01]$.

Group $\mathrm{H}$ showed no evidence of differentiation between CSA and CSB. The distributions for CSA and CSB appeared to be identical. There was a modest proportion of peaks in the 200-399 bin, but the distribution showed a substantial tail stretching into the later bins. In the 200-399 bin, CSA and CSB had $38 \%$ and $42 \%$ of their peaks, respectively $(F<1)$. In the 600-799 bin, CSA and CSB had $19 \%$ and $22 \%$, respectively $(F<1)$.

Individual measures of discrimination. Although the group data displayed imperfect discrimination, many of the subjects in Groups $E$ and $M$ did show nearly perfect differentiation between CSA and CSB, particularly in the earlier portions of the two CSs. Moreover, some of the subjects made both a "correct" and an "incorrect" response during a single trial by producing a $\mathrm{CR}$ with twin peaks. On a CSA trial, an initial CR peak near the 200msec point would be "correct," and a second CR peak near the $600-\mathrm{msec}$ point would be "incorrect." Conversely, on a CSB trial, a CR peak near the $200-\mathrm{msec}$ point would be "incorrect," and a CR peak near the 600 msec point would be "correct." Over all subjects, $46 \%$ of the CRs had twin peaks. There was a nonsignificant tendency for the frequency of twin peaks to rise across Groups $\mathrm{E}, \mathrm{M}$, and $\mathrm{H}[\mathrm{Ms}=40 \%, 47 \%$, and $53 \%$; $F(1,21)=2.76, p>.10]$. The frequency of twin peaks appeared to be about the same for CSA $(M=42 \%)$ and $\mathrm{CSB}[M=50 \%, F(1,21)=1.47, p>.10]$.

To depict the performance of individual subjects, an analysis was conducted in terms of statistical decision theory (SDT). According to SDT, differential responding to stimuli occurs when (1) the subject is sensitive to the physical differences between the two stimuli, and (2) the subject's overall bias to respond is neither too high nor too low. Thus, the high frequency of twin peaks could reflect a failure of sensitivity and/or a high bias to respond.

To determine the sensitivity and response bias for individual subjects, Figure 2 shows two plots of "hits" versus "false alarms." Each point represents the performance of a single subject. In producing the plots, the interval following stimulus onset was divided into two zones at $400 \mathrm{msec}$. This point was halfway between the $200-$ and $600-\mathrm{msec}$ points of US delivery on training trials. In the first zone (0-399 msec), CR peaks to CSA were counted as hits, meaning that they were near the point of US delivery. Conversely, CR peaks appearing in the first zone on CSB trials were counted as false alarms. For each subject, the hit rate for CSA was calculated by counting the number of CRs that had a peak in the first zone and dividing by the total number of CSA test trials. The false-alarm rate of CSB was calculated in the same fashion. Conversely, CR peaks appearing in the second zone $(\geq 400 \mathrm{msec}$ ) were counted as false alarms for CSA and
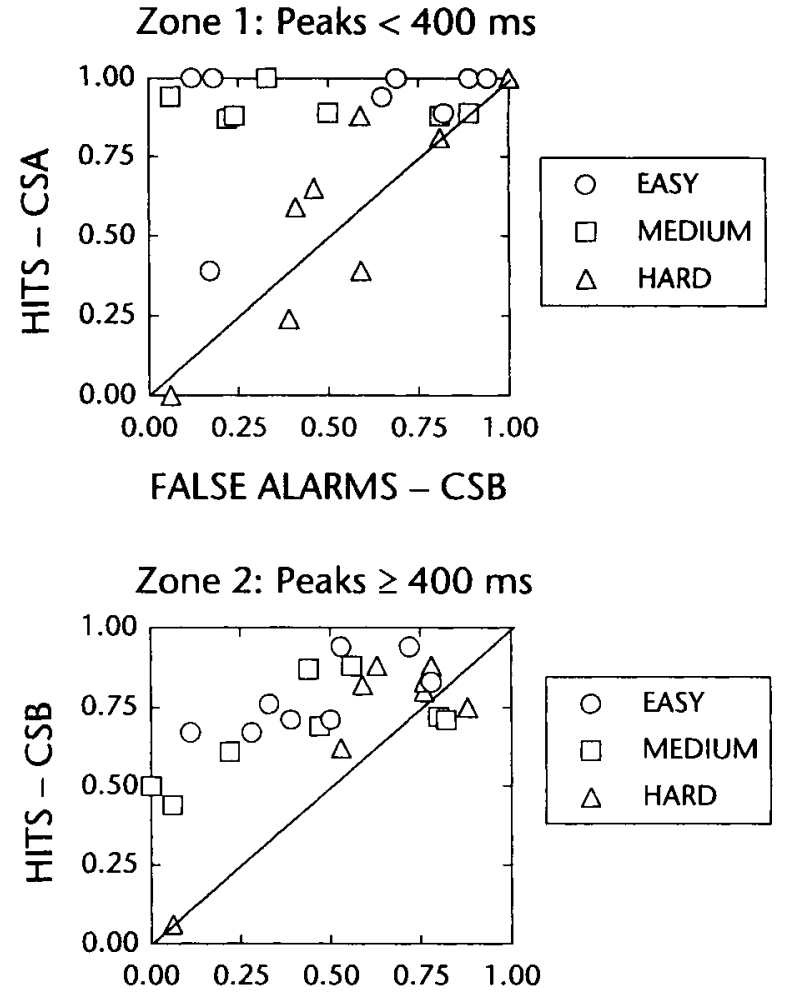

FALSE ALARMS - CSA

Figure 2. Plots of the hit rate as a function of false-alarm rate for each subject in Experiment 1 in two zones following stimulus onset: 0-399 msec and 400-799 msec. (In the upper panel, the hit rate denotes the proportion of CSA test trials with a CR peak in the first zone, and the false-alarm rate denotes the proportion of CSB trials with a CR peak in the first zone. In the lower panel, the hit rate denotes the proportion of the CSB test trials with a CR peak in the second zone, and the false-alarm rate denotes the proportion of CSA tests with a CR peak in the second zone.)

hits for CSB. False-alarm and hit rates for the second zone were calculated in the same way as for the first zone.

The top panel of Figure 2 shows the results for the first zone. For each subject, its hit rate for CSA is plotted as a function of its false-alarm rate for CSB. Inspection of this panel reveals the following features in the performance of the subjects. First, 6 subjects from Groups $E$ and $M$ showed nearly perfect differentiation between CSA and CSB. The points for those subjects are clustered in the upper left corner of the panel. They represent hit rates for CSA between .90 and 1.00 versus false-alarm rates for CSB between .06 and .33. Thus, these subjects show a high degree of sensitivity to the different tonal frequencies coupled with a moderate response bias. Second, with one exception, the points for the remaining subjects in Groups $\mathbf{E}$ and $\mathbf{M}$ appear in the upper right corner. That is, they show both a high hit rate and high false-alarm rate, indicating a high bias to respond that obscured any underlying sensitivity. Third, the points for the subjects 
in Group $\mathrm{H}$ closely followed the diagonal line that represents equal rates for hits and false alarms. For these subjects, there was little indication that they were sensitive to the difference between the $600-$ and $660-\mathrm{Hz}$ tones. Any differences among these subjects reflected only differences in response bias.

The bottom panel of Figure 2 shows the results for the second zone, for which CSB's hit rate is plotted as a function of CSA's false-alarm rate. Differences between the groups were smaller, but still agreed with the pattern seen in the top panel. For Groups $E$ and $M$, most of the subjects showed a hit rate that was about .50 greater than the false-alarm rate. However, for a few subjects with high overall response levels, the hit and false-alarm rates were about equal. For Group H, most subjects showed similar hit and false-alarm rates and high overall response levels.

In the statistical analysis, the hit rate was significantly higher than the false-alarm rate in both zones $[F(1,21)=$ $24.10, p<.01]$. Specifically, in the first zone, the mean hit rate was .79 , and the false-alarm rate was .56. For the second zone, the mean hit rate was .71 , and the mean false-alarm rate was .62. Although the difference between rates appears larger for the first zone than for the second zone, the apparent difference was not significant $(F<1)$. The apparent differences between the groups were significant. There was a significant downward trend across Groups $\mathrm{E}, \mathrm{M}$, and $\mathrm{H}$ in the size of the difference between their respective hit and false-alarm rates $[F(1,21)=12.11$, $p<.01]$.

To estimate the sensitivity of the subjects to the tone frequencies separately from their response biases, an index of sensitivity $\left(A^{\prime}\right)$ was computed for each zone of the CS. The index $A^{\prime}$ is defined as

$$
A^{\prime}=\left\{\left[(\mathrm{H}-\mathrm{F})+(\mathrm{H}-\mathrm{F})^{2}\right] /[4 \mathrm{H}(1-\mathrm{F})]\right\}+0.5,
$$

where $\mathrm{H}=$ the hit rate and $\mathrm{F}=$ the false-alarm rate (Grier, 1971; Raslear, Shurtleff, \& Simmons, 1992). This index was used because it makes no assumptions about the underlying distributions of sensory events. $A^{\prime}$ has a value of .5 when differential responding is at chance, and a value of 1.0 when differential responding is perfect.

For Group E, the mean values of $A^{\prime}$ in the first and second zone were both high: .80 and .75 , respectively. Similarly, Group $M$ yielded mean values of .80 and .68 . Group $\mathrm{H}$ yielded little evidence of any sensitivity; its mean values were .51 and .57 . The statistical analysis revealed that there was a significant downward linear trend across Groups $\mathrm{E}, \mathrm{M}$, and $\mathrm{H}$ in their mean sensitivity $[F(1,21)=$ $17.81, p<.01]$. Differences between sensitivities in the first and second zones were small and not significant $(F<1)$.

\section{Discussion}

Experiment 1 confirmed that differential conditioning in the rabbit NM preparation can occur when both CSs are paired with the US but at different CS-US intervals. Across groups, the levels of differentiation appeared comparable to those obtained in the go/no-go task (Moore, 1972; Poulos et al., 1985). That is to say, the "easy", and "medium" differences between the two tones yielded differential responding in both zones. Among individual subjects, failures in differentiation appeared to result from a high response bias that masked their sensitivity to the tonal frequencies.

The twin-peaked CRs are consistent with previous findings and the expectations of real-time models. When a single CS is paired with the US at two intermixed intervals, the CR develops two distinct peaks, one at each locus of US delivery (Hoehler \& Leonard, 1976; Kehoe et al., 1989; Millenson et al., 1977). The real-time models readily explain this finding, because they assume that the CRs are elicited by elements that overlap the US. Thus, CR peaks tend to coincide with the points of US delivery. When the subject encodes CSA and CSB as identical or similar events, CRs with twin peaks would be expected. Moreover, these results are by no means preordained. Had the animals averaged the two CS-US intervals, the peak distributions might have shown a single mode halfway between the points of US delivery at 200 and $600 \mathrm{msec}$ after CS onset. Had the animals been completely unable to encode the two intervals, the CR peaks might have been distributed unsystematically.

\section{EXPERIMENT 2}

Experiment 2 was identical to Experiment 1 except that the CS-US intervals were increased from values of 200 and $600 \mathrm{msec}$ to values of 600 and $1,200 \mathrm{msec}$. The CS-US interval was increased because previous research using the go/no-go task has indicated that differentiation is improved by concurrently increasing the CS duration and CS-US interval (Vandercar \& Schneiderman, 1967). However, it is not clear whether the sensitivity and/or the response bias was affected by the increase. On the one hand, the increased exposure to the CS and increased time before the US may have enhanced identification of the CSs, thus improving sensitivity. On the other hand, increasing the CS-US intervals also tends to lower the overall level of responding, thus reducing a bias to respond that can mask the underlying discrimination.

\section{Method}

Subjects. The subjects were 12 naive, female albino rabbits. Apparatus and Procedure. Unless otherwise mentioned, the apparatus and procedure were identical to those used in Experiment 1. Following adaptation, the animals were assigned to one of three groups $(n=4)$. They were denoted as Groups E2, M2, and H2, standing for, respectively, "easy," "medium," and "hard" in Experiment 2 . In the three groups, CSA was always the $600-\mathrm{Hz}$ tone, and CSB was, respectively, the tone of $2100 \mathrm{~Hz}, 1000 \mathrm{~Hz}$, and $660 \mathrm{~Hz}$. The CSA-US interval was $600 \mathrm{msec}$, and the CSB-US interval was $1,200 \mathrm{msec}$. On training trials, the CS offset coincided with US offset. The US duration was $100 \mathrm{msec}$. On test trials, the CS duration was always $1,300 \mathrm{msec}$. Initial training with CSA-US and CSB-US trials was run on Days 1-8, and training that included CSA and CSB test trials was run on Days 9-15.

\section{Results}

Group CR peak distributions. Figure 3 shows the mean proportion of CR peaks appearing in each of six 


\section{EXPERIMENT 2 - PEAK LATENCIES}
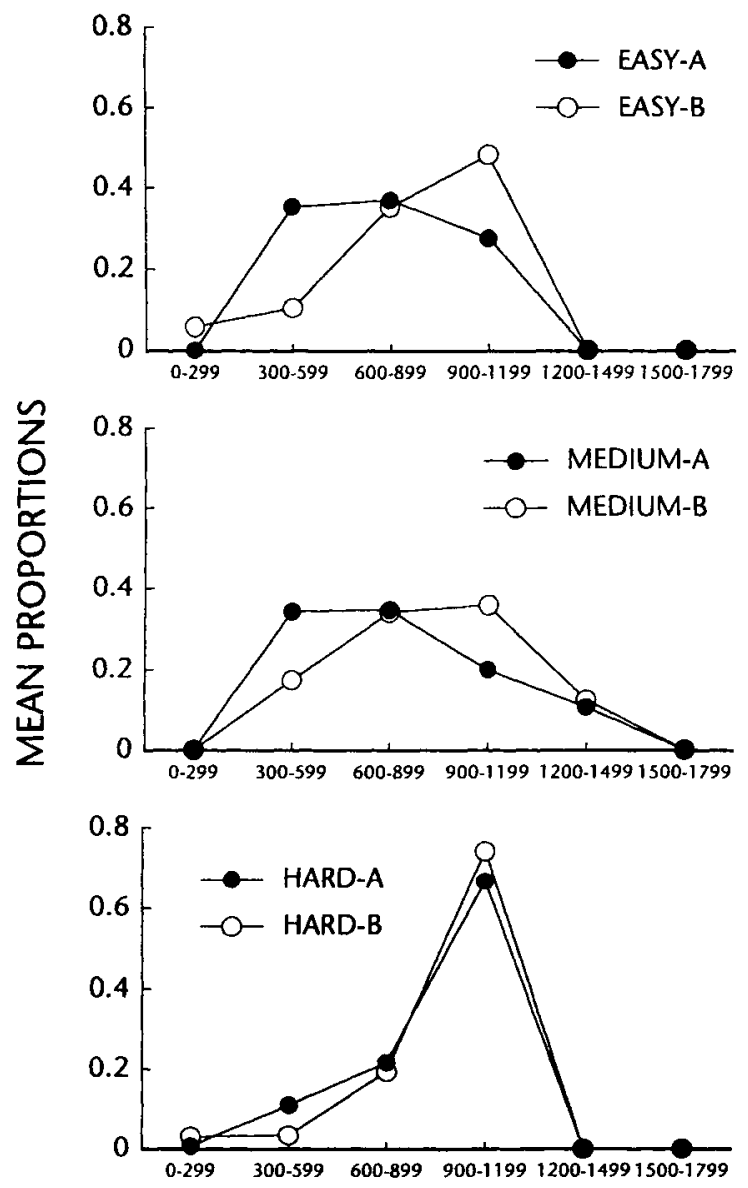

\section{TIME SINCE CS ONSET - 300-ms BINS}

Figure 3. The mean proportion of $\mathrm{CR}$ peaks appearing in each of six 300-msec bins following stimulus onset on CSA and CSB test trials in Experiment 2. (Each bin is labeled by its lower and upper boundary. There is a separate panel for each group.)

300-msec bins following CS onset (1-299, 300-599, etc.). There is a separate panel for each group. Within each panel, there is a separate distribution for CSA and CSB test trials.

Inspection of Figure 3 reveals that the CR peaks were clustered loosely around the points of US delivery at 600 and 1,200 msec after CS onset. In Groups E2 and M2, but not Group $\mathrm{H} 2$, there was some differentiation between the CSA and CSB trials appropriate to their CS-US intervals. Specifically, Group E2 showed a greater proportion of its peaks in the 300-599 bin during CSA $(M=$ $35 \%)$ than CSB $(M=10 \%)$. This difference approached but failed to reach significance $[F(1,9)=3.39, p<.10]$. Conversely, in the 900-1199 bin, a significantly smaller proportion of peaks appeared during CSA $(M=28 \%)$ than during CSB $[M=48 \%, F(1,9)=5.26, p<.05]$. The corresponding differences in Group M2 were similar but smaller, and failed to reach even a liberal criterion of significance ( $p s>.10$ ). In Group $H$, the CR peaks during both CSA and CSB were concentrated in the 900 1199 bin. Any apparent differences in Group H2 failed to approach significance.

Individual measures of discrimination. Unlike in Experiment 1 , CRs with twin peaks were rare. Only $6 \%$ of all CRs had twin peaks. Half of the subjects showed no CRs with twin peaks. In the subject with greatest frequency, only $28 \%$ of its CRs had twin peaks.

Figure 4 shows two plots of hits versus false alarms for Experiment 2. The interval following stimulus onset was divided into two zones at $900 \mathrm{msec}$, which was halfway between the 600 - and 1,200-msec points of US delivery on training trials. In the first zone (0-899 $\mathrm{msec}), C R$ peaks during CSA were counted as hits, and CR peaks during CSB were counted as false alarms. Conversely, $C R$ peaks appearing in the second zone $(\geq 900 \mathrm{msec})$ were counted as false alarms for CSA and hits for CSB.

For both zones, the use of the longer CS-US intervals in Experiment 2 produced a large reduction in the over-

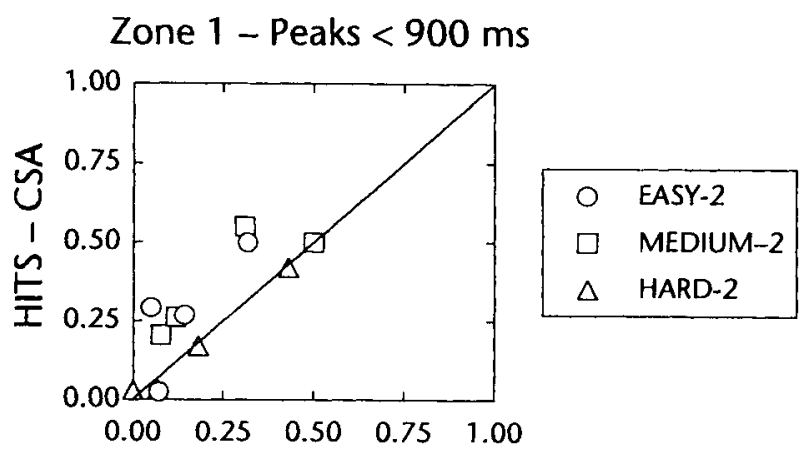

FALSE ALARMS - CSB

Zone 2 - Peaks $\geq 900 \mathrm{~ms}$

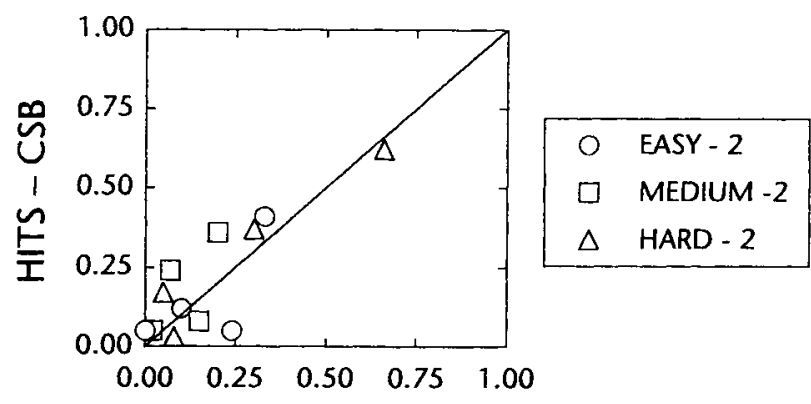

FALSE ALARMS - CSA

Figure 4. Plots of the hit rate as a function of false-alarm rate for each subject in Experiment 1 in two zones following stimulus onset: 0-899 msec and 900-1,799 msec. (In the upper panel, the hit rate denotes the proportion of CSA test trials with a CR peak in the first zone, and the false-alarm rate denotes the proportion of CSB trials with a CR peak in the first zone. In the lower panel, the hit rate denotes the proportion of the CSB test trials with a CR peak in the second zone, and the false-alarm rate denotes the proportion of CSA tests with a CR peak in the second zone.) 
all level of responding. To the extent that the low levels of responding can be discounted, differential responding in the first zone was ordered in much the same way as in Experiment 1. That is, 3 subjects each in Groups E2 and M2 showed differential responding in that their hit rate was higher than the false-alarm rate, at least in the first zone. As in Experiment 1, none of the subjects in Group H2 showed any sign of differentiation. The points for the subjects in Group $\mathrm{H} 2$ all lie on the diagonal line that represents equal rates for hits and false alarms. (The plot for the first zone seems to show only three points for Group H2, because 2 subjects showed no CR peaks during the first zone. Their points are superimposed at the origin of the plot.)

Statistical analyses revealed that, across groups, the hit rate was significantly greater than the false-alarm rate in the first zone but not in the second zone. For the first zone, the mean hit rate was .27 , and the false-alarm rate was $.14[F(1,9)=9.23, p<.05]$. There was also some evidence of a linear trend across groups in the difference between their respective hit and false-alarm rates in the first zone. This trend approached but did not reach statistical significance $[F(1,9)=4.15, p<.10]$. For the second zone, the mean hit rate was .21 , which was only slightly greater than the mean false-alarm rate of $.18(F<1)$. Any apparent differences between groups failed to reach significance $(F \mathrm{~s}<1)$.

The sensitivity measure $A^{\prime}$, which removed response bias from the differential performance, revealed low values and at best only some small differences among the three groups. The mean values of $A^{\prime}$ across Groups E2, M2, and $\mathrm{H} 2$ were, respectively, $.44, .61$, and .44 . Statistical analysis yielded only the suggestion that Group M2 showed greater sensitivity than the other two groups $[F(1,9)=$ $3.42, p<.10]$.

\section{GENERAL DISCUSSION}

The results of the present experiments showed that differential conditioning based on two CS-US intervals varied systematically as function of the tonal differences between the two CSs. At a group level, the distribution of CR peak latencies around the points of US delivery varied systematically as a function of the difference between tonal frequencies. For the differences that were "easy" ( 600 vs. $2100 \mathrm{~Hz}$ ) and "medium" (600 vs. $1000 \mathrm{~Hz}$ ), the distributions overlapped but generally conformed to their CS-US intervals. For the "hard" difference (600 vs. $660 \mathrm{~Hz}$ ), the distributions overlapped entirely.

The increase in CS-US intervals from Experiment 1 to Experiment 2 was accompanied by a reduction in the overall level of responding and differentiation. It is less clear what happened to the sensitivity to tonal differences, but sensitivity certainly did not increase. For use in neural research, intervals that are at or slightly longer than the optimal for NM conditioning would appear to be more suitable for producing robust levels of responding plus consistent differentiation in the CRs. Based on the results from Experiment 1 and those of Mauk and Ruiz (1992), the shorter interval could be 150-250 msec and the longer interval could be $600-1,000 \mathrm{msec}$.

The subjects appeared to combine differentiation between the CSs and place the CR peaks around the loci of the USs without having to compromise the accuracy of either process. That is to say, the sensitivity to tonal frequencies in the present experiments resembled that seen in the more conventional go/no-go task. Moreover, the distribution of peak latencies was similar to those seen with single CSs. In particular, the peak latencies were relatively tightly distributed around the points of US delivery near CS onset (e.g., $200 \mathrm{msec}$ ) and became more dispersed at points more distant from CS onset (e.g., Kehoe \& Napier, 1991).

In previous studies, Kehoe et al. (1989) and Mauk and Ruiz (1992) demonstrated that differential conditioning based on different CS-US intervals could occur. However, they used stimuli that differed dramatically. Kehoe et al. (1989) used tone versus light, and Mauk and Ruiz used a $400-\mathrm{Hz}$ tone versus an $8000-\mathrm{Hz}$ tone. Before the present experiments, it was unclear how the animals would respond to smaller physical differences between the CSs. Among the conceivable outcomes, it was likely that the animals would respond nondifferentially by placing a CR peak at each of the two loci of the US. This outcome was obtained by Kehoe et al. (1989) when they attempted a temporal discrimination between a compound and its individual CSs. However, the present results revealed that there was a graceful degradation in differential responding as the difference was reduced.

In order to explain the ability of the animals to make simultaneous sensory and temporal discriminations, the most suitable real-time model is that of Desmond and Moore (1990), who contend that sensory encoding and temporal encoding of the CSs partially overlap. The model assumes that each CS activates a "tapped delay line," which is a sequence of neuron-like elements that each feed their output to the next unit in the line and also to a common associative apparatus (Desmond \& Moore, 1988). Thus, the time since CS onset is encoded by outputs from different elements of the delay line. Desmond (1990) expands this one-dimensional scheme for temporal encoding into a two-dimensional "planar array" that contains a set of cross-linked parallel delay lines. The initial input for each delay line would arise from a different CS. As the input signal propagates down the delay line, the signal also spreads to the elements of nearby lines. Thus, the number of lines being activated would tend to increase following CS onset. This spread of activation, however, is not self-sustaining, and the number of activated lines eventually diminishes.

According to this scheme, the rate of $\mathrm{CR}$ acquisition for a single CS depends on the number of lines activated at the time of US delivery. For NM conditioning, this point would occur 200-300 msec after CS onset (Kehoe, Cool, \& Gormezano, 1991; Smith, 1968; Smith, Coleman, \& Gormezano, 1969). For two CSs, their differen- 
tiation depends on the overlap in the lines that they activate on their respective trials. This differentiation would be poorest at 200-300 msec after CS onset, that is, when the most lines are activated and the overlap between two CSs would be the greatest.

The present results do not entirely support the prediction of Desmond's (1990) model, namely, that differentiation should be greater at longer CS-US intervals than at shorter CS-US intervals. The clearest differentiation between CSA and CSB was achieved around the 200-msec point of US delivery in Experiment 1. On a more conservative statistical basis, the levels of differentiation around the $200-$ and $600-\mathrm{msec}$ points failed to differ. The longer CS-US intervals of 600 and $1,200 \mathrm{msec}$, used in Experiment 2, reduced differentiation around both points. However, there were such low levels of responding that it would be unwise to put much confidence in those results. The results from go/no-go tasks are mixed. In agreement with Desmond's model, Vandercar and Schneiderman (1967) found that the differentiation in NM conditioning between a 550 - and a $3400-\mathrm{Hz}$ tone was greater for a $750-$ msec CS-US interval than for CS-US intervals of 250 , 2,250 , and 6,750 msec. However, Chisholm, Hupka, and Moore (1969) failed to find any change in differentiation across CS-US intervals of 250,500 , and $1,000 \mathrm{msec}$ for either an easy discrimination ( $300 \mathrm{vs.} 1700 \mathrm{~Hz}$ ) or a hard discrimination (900 vs. $1100 \mathrm{~Hz}$ ). At present, it would seem safest to consider Desmond's prediction to be an open matter.

The present results do confirm a central premise that Desmond's (1990) model shares with all other real-time models. They all assume that the temporal encoding of the CS consists of a cascade of what might be considered microstimuli. Each of these hypothetical stimuli presumably acts much like an ordinary, external CS. In particular, each stimulus is thought to be capable of acquiring its own associative strength that summates with those of other stimuli (cf. Kehoe et al., 1993). Accordingly, the moment-by-moment amplitude of the CR reflects the summated associative strengths of concurrent stimuli. Because the stimuli closest to the US should acquire the greatest associative strength, it is a key prediction that the CR peaks should cluster around the points of US delivery. This prediction was repeatedly confirmed in the present experiments across the easy, medium, and hard discriminations.

For purposes of identifying the neural substrates of sensory and temporal encoding, the real-time models suggest that the microstimuli might be manipulated more directly by sequentially stimulating different groups of neurons suspected of encoding the CS. Take, for example, Mauk and Ruiz's (1992) hypothesis that the cerebellar granule cells may provide the temporal encoding of the CS. In principle, this hypothesis could be tested by first training subjects by using sequential stimulation of different cells as the CS. Test trials in which the order and/or timing of the stimulation is altered should yield predictable variations in the CR timing. By the same token, if fine sen- sory encoding of the CS relies on the mossy fibers, it should be possible to conduct differential conditioning by pairing stimulation of different portions of the mossy fibers with the US at different CS-US intervals.

Beyond issues of the real-time models, the present results confirm previous findings that the time course of the $\mathrm{CR}$ is a learnable property that can be attached to different CSs (Kehoe et al., 1989; Mauk \& Ruiz, 1992). Contrary to textbook depictions of conditioned reflexes as stereotyped actions, CRs are graded in a manner that is well attuned to the CS-US interval and also to the sensory features of the CS. Moreover, the CRs are generated by the CS literally in the blink of an eye. These results point to a neural substrate that is highly plastic, richly differentiated, and very quick in its operation.

\section{REFERENCES}

Berger, T. W., \& Thompson, R. F. (1978). Neuronal plasticity in the limbic system during classical conditioning of the rabbit nictitating membrane response: I. The hippocampus. Brain Research, 145, 323-346.

Berthier, N. E., \& Moore, J. W. (1986). Cerebellar Purkinje cell activity related to the classically conditioned nictitating membrane response. Experimental Brain Research, 63, 341-350.

BerThIER, N. E., MoORE, J. W. (1990). Activity of cerebellar deep nuclear cells during classical conditioning of nictitating membrane extension in rabbits. Experimental Brain Research, 83, 44-55.

Buonomano, D. V., \& MaUK, M. D. (1991). Neural network based on the circuitry of the cerebellum simulates the timing of motor responses. Society for Neuroscience Abstracts, 17, 870.

Cegavske, C. F., Patterson, M. M., \& Thompson, R. F. (1979). Neuronal unit activity in the abducens nucleus during classical conditioning of the nictitating membrane response in the rabbit, Oryctolagus cuniculus. Journal of Comparative \& Physiological Psychology, 93, 595-609.

Chisholm, D. G., HupKa, R. B., \& Moore, J. W. (1969). Auditory differential conditioning of the rabbit nictitating membrane response: II. Effects of interstimulus interval and cue similarity. Psychonomic Science, 15, 125-126.

Coleman, S. R., Gormezano, I. (1971). Classical conditioning of the rabbit's (Oryctolagus cuniculus) nictitating membrane response under symmetrical CS-US interval shifts. Journal of Comparative \& Physiological Psychology, 77, 447-455.

DESMOND, J. E. (1990). Temporal adaptive responses in neural models: The stimulus trace. In M. Gabriel \& J. W. Moore (Eds.), Learning and computational neuroscience (pp. 421-456). Cambridge, MA: MIT Press.

Desmond, J. E., \& MoORE, J. W. (1988). Adaptive timing in neural networks: The conditioned response. Biological Cybernetics, 58, 405-415.

Desmond, J. E., \& MoORE, J. W. (1991). Single-unit activity in red nucleus during the classically conditioned rabbit nictitating membrane response. Neuroscience Research, 10, 260-279.

Disterhoft, J. F., QuinN, K. J., Weiss, C., \& ShIPley, M. T. (1985). Accessory abducens nucleus and conditioned eye retraction/nictitating membrane extension in rabbit. Journal of Neuroscience, 5 , 941-950.

Gluck, M. A., Reifsnider, E. S., \& Thompson, R. F. (1990). Adaptive signal processing and the cerebellum: Models of classical conditioning and VOR adaptation. In M. A. Gluck \& D. E. Rumelhart (Eds.), Neuroscience and connectionist theory (pp. 131-185). Hillsdale, NJ: Erlbaum.

Gormezano, I. (1966). Classical conditioning. In J. B. Sidowski (Ed.), Experimental methods and instrumentation in psychology (pp. 385420). New York: McGraw-Hill.

Gormezano, I., \& GibBs, C. M. (1988). Transduction of the rabbit's 
nictitating membrane response. Behavior Research Methods, Instruments, \& Computers, 20, 18-21.

GrIeR, J. B. (1971). Nonparametric indexes for sensitivity and bias: Computing formulas. Psychological Bulletin, 75, 424-429.

Grossberg, S., \& SChmajuk, N. A. (1989). Neural dynamics of adaptive timing and temporal discrimination during associative learning Neural Networks, 2, 79-102.

HoEhlER, F. K., \& LEONARD, D. W. (1976). Double responding in classical nictitating membrane conditioning with single-CS dual-ISI pairing. Pavlovian Journal of Biological Science, 11, 180-190.

Iто, M. (1984). The cerebellum and neural control. New York: Raven Press.

KEHOE, E. J. (1986). Summation and configuration in conditioning of the rabbit's nictitating membrane response to compound stimuli. Journal of Experimental Psychology: Animal Behavior Processes, 12, 186-195.

Kehoe, E. J., CoOl, V., \& Gormezano, I. (1991). Trace conditioning of the rabbit's nictitating membrane response as a function of CS-US interstimulus interval and trials per session. Learning \& Motivation, 22, 269-290.

Kehoe, E. J., Feyer, A., \& Moses, J. L. (1981). Second-order conditioning of the rabbit's nictitating membrane response as a function of the CS2-CS1 and CS1-US intervals. Animal Leaming \& Behavior, 9, 304-315.

Kehoe, E. J., \& Graham, P. (1988). Summation and configuration in negative patterning of the rabbit's conditioned nictitating membrane response. Journal of Experimental Psychology: Animal Behavior Processes, 14, 320-333.

Kehoe, E. J., Graham-Clarke, P., \& Schreurs, B. G. (1989). Temporal patterns of the rabbit's nictitating membrane response to compound and component stimuli under mixed CS-US intervals. Behavioral Neuroscience, 103, 283-295.

Kehoe, E. J., Horne, P. S., Macrae, M., \& Horne, A. J. (1993). Real-time processing of serial stimuli in classical conditioning of the rabbit's nictitating membrane response. Joumal of Experimental Psychology: Animal Behavior Processes, 19, 265-283.

KEHOE, E. J., * NAPIER, R. M. (1991). Temporal specificity in crossmodal transfer of the rabbit nictitating membrane response. Journal of Experimental Psychology: Animal Behavior Processes, 17, 26-35.

Marshall-Goodell, B., SChreURs, B. G., G Gormezano, I. (1982). Ruler vs. the Apple I/FIRST system analysis of analog signals in classical conditioning. Behavior Research Methods \& Instrumentation, 14, 519-525.

Mauk, M. D., Ruiz, B. P. (1992). Learning-dependent timing of Pavlovian eyelid responses: Differential conditioning using multiple interstimulus intervals. Behavioral Neuroscience, 106, 666-681.

McCormick, D. A., \& Thompson, R. F. (1984). Neuronal responses of the rabbit cerebellum during acquisition and performance of a classically conditioned nictitating membrane-eyelid response. Journal of Neuroscience, 4, 2811-2822.

Millenson, J. R., Kehoe, E. J., \& Gormezano, I. (1977). Classical conditioning of the rabbit's nictitating membrane response under fixed and mixed CS-US intervals. Learning \& Motivation, 8, 351-366.

MoOre, J. W. (1972). Stimulus control: Studies of auditory generalization in rabbits. In A. H. Black \& W. F. Prokasy (Eds.), Classical conditioning II: Current research and theory (pp. 206-230). New York: Appleton-Century-Crofts.

MOORE, J. W., BLAZIS, D. E. J. (1989). Simulation of a classically conditioned response: A cerebellar neural network implementation of the Sutton-Barto-Desmond model. In J. H. Byrne \& W. O. Berry
(Eds.), Neural models of plasticity: Experimental and theoretical approaches (pp. 187-207). New York: Academic Press.

Moore, J. W., Desmond, J. E., Berthier, N. E. (1989). Adaptively timed conditioned responses and the cerebellum: A neural network approach. Biological Cybernerics, 62, 17-28.

Pavlov, I. P. (1927). Conditioned reflexes (G. V. Anrep, Trans.). London: Oxford University Press.

Poulos, C. X., Kehoe, E. J., * Gormezano, I. (1985). Appetitive differential conditioning of the rabbit's jaw movement response. Pavlovian Joumal of Biological Science, 20, 29-38.

Raslear, T. G., Shurtleff, D., \& Simmons, L. (1992). Intertrialinterval effects on sensitivity $\left(A^{\prime}\right)$ and response bias $\left(B^{\prime \prime}\right)$ in a temporal discrimination by rats. Journal of the Experimental Analysis of Behavior, 58, 527-535.

SCANDRETt, J., \& Gormezano, I. (1980). Microprocessor control and A/D data acquisition in classical conditioning. Behavior Research Methods \& Instrumentation, 12, 120-125.

SMiтh, M. C. (1968). CS-US interval and US intensity in classical conditioning of the rabbit's nictitating membrane response. Journal of Comparative \& Physiological Psychology, 66, 679-687.

Smith, M. C., Coleman, S. R., \& Gormezano, I. (1969). Classical conditioning of the rabbit's nictitating membrane response at backward, simultaneous, and forward CS-US intervals. Journal of Comparative \& Physiological Psychology, 69, 226-231.

Steinmetz, J. E., Logan, C. G., \&hompson, R. F. (1988). Essential involvement of mossy fibers in projecting the CS to the cerebellum during classical conditioning. In C. D. Woody, D. L. Alkon, \& J. L. McGaugh (Eds.), Cellular mechanisms of conditioning and behavioral plasticity (pp. 143-148). New York: Plenum.

Steinmetz, J. E., Logan, C. H., Rosen, D. J., Thompson, J. K. LAvoND, D. G., \& ThOMPSon, R. F. (1987). Initial localization of the acoustic conditioned stimulus projection system to the cerebellum during classical eyelid conditioning. Proceedings of the National Academy of Sciences USA, 84, 3531-3535.

Steinmetz, J. E., Rosen, K. J., Chapman, P. F., Lavond, D. G., \& THOMPSON, R. F. (1986). Classical conditioning of the rabbit eyelid response with a mossy fiber stimulation CS: I. Pontine nuclei and middle cerebellar peduncle stimulation. Behavioral Neuroscience, $\mathbf{1 0 0}$, 871-880.

SUBosxi, M. D. (1967). The analysis of classical discrimination conditioning experiments. Psychological Bulletin, 68, 235-242.

SutTon, R. S., \& BARTo, A. G. (1990). Time-derivative models of Pavlovian reinforcement. In M. Gabriel \& J. W. Moore (Eds.), Learming and computational neuroscience (pp. 497-537). Cambridge, MA: MIT Press.

VANDERCAR, D. H., \& SCHNEIDERMAN, N. (1967). Interstimulus interval functions in different response systems during classical discrimination conditioning of rabbits. Psychonomic Science, 9, 9-10.

Weisz, D. J., Clark, G. A., \& Thompson, R. F. (1984). Increased responsivity of dentate granule cells during nictitating membrane response conditioning in rabbits. Behavioural Brain Research, 12, 145-154.

Young, R. A., Cegavaske, C. F., \&hompson, R. F. (1976). Toneinduced changes in excitability of abducens motoneurons and of the reflex path of the nictitating membrane response in rabbit (Oryctolagus cuniculus). Journal of Comparative \& Physiological Psychology, 90, 424-434.

(Manuscript received March 29, 1993; revision accepted for publication June 25,1993 .) 